\title{
Introduction to the special issue: Harnessing the power of brand and co-created innovation
}

\author{
Mark Uncles ${ }^{1} \cdot$ Liem Viet Ngo ${ }^{1}$
}

(C) Macmillan Publishers Ltd 2017

Claims that brand and innovation management are strongly interrelated are not new. Branding is critical to the success of an innovation (e.g. HP's "Invent", Toshiba's "Leading Innovation", GE's "Imagination Breakthrough"), while innovation is necessary to keep a brand fresh, up to date and relevant. And the point has been made forcefully that innovations must be branded or their commercial value will be lost (Aaker 2007). We now know much about the interdependencies between brand and innovation management (e.g. Hatch and Schultz 2010; Hultink 2010; Iglesias et al. 2013; Nedergaard and Gyrd-Jones 2013). A handy framework for thinking about these interdependencies is the brand-innovation virtuous circle, whereby: (i) brands support the introduction and adoption of innovation, (ii) innovations influence brand perceptions, attitudes and usage, and (iii) brands provide strategic focus and guidance to innovations (Brexendorf et al. 2015). Despite this body of work, there remain calls for more detailed and specific investigations (Besharat and Langan 2014; Brexendorf et al. 2015). These calls are particularly pertinent today because of new opportunities in digitally empowered marketplaces and in emerging markets (e.g. innovative brand-customer co-creation using social media, video sharing and microblogging on platforms such as Facebook, YouTube and Twitter).

To harness the power of brand and co-created innovation in the digital era, we would like answers to a range of

Mark Uncles

m.uncles@unsw.edu.au

Liem Viet Ngo

liem.ngo@unsw.edu.au

1 UNSW Business School, UNSW Sydney, Sydney, NSW 2052, Australia conceptual and practical questions: How can branded cocreated innovation opportunities be identified and evaluated? What best practices exist for successful co-development and co-implementation of branded innovations? What innovative approaches are there to engage customers with brand-building and brand-leveraging activities? What motivates customers to invest in these activities? How effective for innovative new product development are different brand engagement platforms (e.g. customer to firm and customer to customer)? What are effective co-branding practices and strategies for new product development and new market entry? What drives the co-creation of stakeholder identity and brand identity? What types of brand association are important for firms operating in emerging markets and, in such contexts, how significant is co-created innovation? What is the role of corporate branding in relation to co-created innovation? How can a corporate brand promote sustainable innovations?

The papers in this special issue of the Journal of Brand Management help us understand recent trends and the diversity of responses and begin to provide answers to some of the questions posed above.

In the first paper (The Co-Creation Continuum: From Tactical Market Research Tool To Strategic Collaborative Innovation Method) Nicholas Ind, Oriol Iglesias and Stefan Markovic contribute to our knowledge base by focusing on the managerial perspective of co-creation in a branding context. An informative and timely overview is presented of co-creation research, and this provides a helpful introduction to the themes of this special issue. Findings from 20 in-depth interviews with managers that have led cocreation initiatives in 20 brands provide insights and instructions for managers in realizing the potential of cocreation. The article finds diverse views of co-creationfrom tactical market research tool to strategic collaborative 
innovation method, and shows that brands can be positioned along a continuum between these two polarities.

In the second article (Helping Those Who Help Us: CoBranded and Co-Created Twitter Promotion In CSR Partnerships) Suzan Burton, Alena Soboleva, Kate Daellenbach, Debra Basil, Terry Beckman and Sameer Deshpande highlight the importance of innovative, technologyenabled collaboration to harness the power of brands. Through their thorough data-driven analysis, the authors examine the extent of co-branded and co-created promotion by a popular non-profit organization (NPO) and its network of sponsors on Twitter and draw a comparison with promotion of the same activity using traditional news media. The contribution of the article is to highlight opportunities that exist for "partners" and "causes" to collaborate and make strategic use of new technologies to expand the reach of their respective brands. In a practical sense, this study gives brand managers insight into the potential benefits that could accrue from working with partners to innovate and co-create promotional messages, and demonstrates the value of integrating Twitter as a promotional channel into their brand management strategies.

In the third article (Go With The Flow: Engineering Flow Experiences For Customer Engagement Value Creation In Branded Social Media Environments) Jamie Carlson, Natalie Jane de Vries, Mohammad Rahman and Alex Taylor examine the role of flow as having direct influence on the creation of customer engagement value (CEV). In particular, the study substantiates the relationship of flow in explaining and predicting the three critical CEV components of customer lifetime value (CLV), customer influence value (CIV) and customer knowledge value $(\mathrm{CKV})$ in a branded social media setting. With more active and empowered consumers, such a focus is now of strategic importance to achieve co-creation and innovation objectives in brand management and ultimately to fulfil brand performance goals. The article offers practical insights for brand and social media marketing managers to allocate resources to those controllable flow-inducing activities to unlock CEV value creation for brands.

In the fourth paper (Gamification As A Platform For Brand Co-Creation Experiences) Helena Nobre and André Ferreira propose an innovative approach to brand management through the application of gamified systems. Gamified experiences have the potential to increase engagement with brands, leading to several forms of cocreation: co-creation of the game itself, of the brand that underlies the game and of innovations that spin off from the brand. This article explores the motivations of consumers to become involved with gamification as a new playful way of brand co-creation and comments on how this may have an impact on consumer engagement with brands. Consumers value entertainment, challenges, continuous experiences and brand involvement, and seek out gamified systems that promote fun, rewards, competition, social interactions and recognition, customization and sense of community. At the same time, gamification enables firms to collect data on the opinions of consumers, segment the market, define consumer profiles, strengthen brand positioning and reputation, and enhance brand relationships by creating tangible experiences that encourage effective communication with customers and with the targets of word of mouth.

In the final paper (Effective Strategies For Developing Meaningful Names And Associations For Co-Branded Products In New and Emerging Markets) Kun Chen, Stephen Newell, Gang Kou and Lei Zhang examine the effects of naming strategies of co-branded products and brand name orders on customer-based brand equity in the context of emerging markets. The results suggest that ingredient co-branding is beneficial to partner institutions by transferring equity from one brand to the other. The meaningfulness of brand names, as well as brand order, significantly affects the brand equity of the ingredient branding alliance.

We believe this special issue will stimulate more research into brand and co-created innovation and lead to a better understanding of the interdependencies between brand and innovation management, especially in view of new opportunities in digitally enabled marketplaces and in emerging markets. Reflecting on the themes addressed in these papers, and looking to the future, we encourage researchers to develop knowledge and insights along the following lines:

- To understand the mechanisms that can lead to the development of an open and participatory culture, as well as the factors that can facilitate the tearing down of internal silos and the promotion of transversal collaborations. The implication is that many organizations are failing to realize the potential of co-creation. To bring about change they will require new thinking around core assumptions, stakeholder involvement, the role of outsiders, relationships, culture and organizational focus.

- To understand why some brands and brand partners do not appear to publicize their own activities, or engage in co-branded or co-created communications in the form of retweeting other partners' messages. Are these examples of missed opportunity, or might there be risks with such open forms of communication?

- To investigate the integration of branded social media experiences with other brand touch points and channels to better understand the delivery of compelling brand 
experiences that are seamless and unified and which therefore reflect a coherent brand image.

- To assess the influence of groups and peers on the maintenance and use of gamification systems as a basis for innovation. Also, to consider the main reasons that lead to the abandonment of such systems, which might shed light on a model of gamification recovery and enhancement.

- To investigate whether and to what degree cultural variables affect how brand names are perceived, and then how these perceptions might be leveraged when launching brands or refreshing existing ones.

More generally, these specific themes must continue to be considered against a backdrop of fundamental social and technological change. The brand-innovation virtuous cycle noted earlier continues to capture the essential interdependencies between brand and innovation management (Brexendorf et al. 2015), but the digital era creates change and a plethora of new contexts that offer many new opportunities for co-created innovation.

Acknowledgements We express our gratitude to all the reviewers who kindly provided authors with very constructive comments and suggestions and to the Editors of the Journal of Brand Management who enthusiastically supported this project from the beginning.

\section{References}

Aaker, D. 2007. Innovation: Brand it or lose it. California Management Review 50 (1): 8-24.
Besharat, A., and R. Langan. 2014. Towards the formation of consensus in the domain of co-branding: Current findings and future priorities. Journal of Brand Management 21 (2): 112-132.

Brexendorf, T.O., B.L. Bayus, and K.L. Keller. 2015. Understanding the interplay between brand and innovation management: Findings and future research directions. Journal of the Academy of Marketing Science 43 (5): 548-557.

Hatch, M.J., and M. Schultz. 2010. Toward a theory of brand cocreation with implications for brand governance. Journal of Brand Management 17 (8): 590-604.

Hultink, E.J. 2010. From the special issue guest editor: Special issue on branding and new product development. Journal of Product Innovation Management 27 (1): 3-5.

Iglesias, O., N. Ind, and M. Alfaro. 2013. The organic view of the brand: A brand value co-creation model. Journal of Brand Management 20 (8): 670-688.

Nedergaard, N., and R. Gyrd-Jones. 2013. Sustainable brand-based innovation: The role of corporate brands in driving sustainable innovation. Journal of Brand Management 20 (9): 762-778.

Mark Uncles Deputy Dean (Education), UNSW Business School. Research interests include brand management, consumer loyalty, retail management and marketing science. Publications in Marketing Science, Journal of Retailing, Journal of Service Research, Sloan Management Review, Journal of Business Research, European Journal of Marketing, amongst others.

Liem Viet Ngo Associate Professor and Postgraduate Research Coordinator, School of Marketing, UNSW Business School. Research is focused on resources and capabilities management in marketing, and innovation and entrepreneurship in cross-cultural contexts. Publications in Journal of Business Research, Industrial Marketing Management, British Journal of Management, Journal of Product Innovation Management, European Journal of Marketing, amongst others. 